\title{
Percutaneous biopsy of mediastinal tumours under sonographic guidance
}

Until the early 1980s biopsies of mediastinal tumours were performed exclusively under fluoroscopic control, following the report by Nordenström in $1967 . .^{1-4}$ Computed tomography now has largely replaced fluoroscopy for this purpose as it allows accurate localisation of the lesion and depicts its anatomical relation to the large mediastinal vessels. ${ }^{56}$ Accidental puncture of the mediastinal vessels, which is not uncommon under fluoroscopic guidance, ${ }^{2}$ can be largely avoided with exact computed tomography guided planning of the biopsy route. In addition, the exact location of the needle tip in the target lesion can be reviewed before biopsy.

In 1986 and 1988 we described the techniques of supraparasternal and parasternal mediastinal sonography, which allows a considerable part of the mediastinum to be assessed. ${ }^{78}$ We have applied this technique to guidance of percutaneous mediastinal tumour biopsy, ${ }^{9}$ because sonographic guidance has all the advantages of spatial orientation offered by computed tomography and also provides continuous monitoring of the biopsy under real time conditions.

\section{SELECTION OF PATIENTS FOR SONOGRAPHICALLY GUIDED} BIOPSY

The essential criterion for selection of patients is the availability of an avascular approach to the mediastinal tumour at sonography. With the use of both a suprasternal and a parasternal approach sonography has proved to be highly sensitive in the detection of tumours in most parts of the mediastinum. ${ }^{10}$ The approach to certain mediastinal regions (paratracheal, subcarinal, and aorticopulmonary) is, however, obstructed by mediastinal vessels and sonographically guided biopsy is not appropriate. Sonographic guidance is mainly suitable for the biopsy of anterior mediastinal and supra-aortic tumours. ${ }^{9}$

\section{TECHNIQUE OF SONOGRAPHICALLY GUIDED BIOPSY}

Preliminary sonographic examination with a $3.5 \mathrm{MHz}$ convex probe serves to locate the tumour accurately and to define its anatomical relations to enable the optimal biopsy approach to be selected. The biopsy is performed by means of a sterilisable biopsy probe with a central perforation for needle guidance (LSC 7000, Picker International, Munich). The needle guide can be adjusted to any angle in the range $0-30^{\circ}$. The trajectory line is displayed electronically on the monitor (figs 1 and 2).

Most sonographically guided biopsies are performed via the right or left parasternal approach with the patient in the supine, right, or left decubitus position. The biopsy route is planned to avoid all mediastinal vessels, even for small calibre needles (20 gauge). To avoid inadvertent puncture of the internal mammary artery, the immediate parasternal (fig 2) or lateral approach (more than $2.5 \mathrm{~cm}$ from the lateral margin of the sternum-see figure 2) should be selected. ${ }^{11}$ When a large cutting needle is used the position of the mammary vessels can be displayed by preliminary sonographic examination with 5.0 or $7 \cdot 5 \mathrm{MHz}$ transducers (fig 3 )..$^{12}$ The large mediastinal vessels should be avoided by selecting an appropriate angle of entry of the biopsy route (fig 1). Mediastinal tumours of the supra-aortic regions are biopsied via the suprasternal approach. The patient is in the supine position with cushions placed under the shoulder girdle. The transducer is placed immediately above the presternum in the jugular fossa.
The choice of biopsy needle depends on tumour size, tumour location, and the clinical questions being asked. Mediastinal tumours of unknown cause should be biopsied
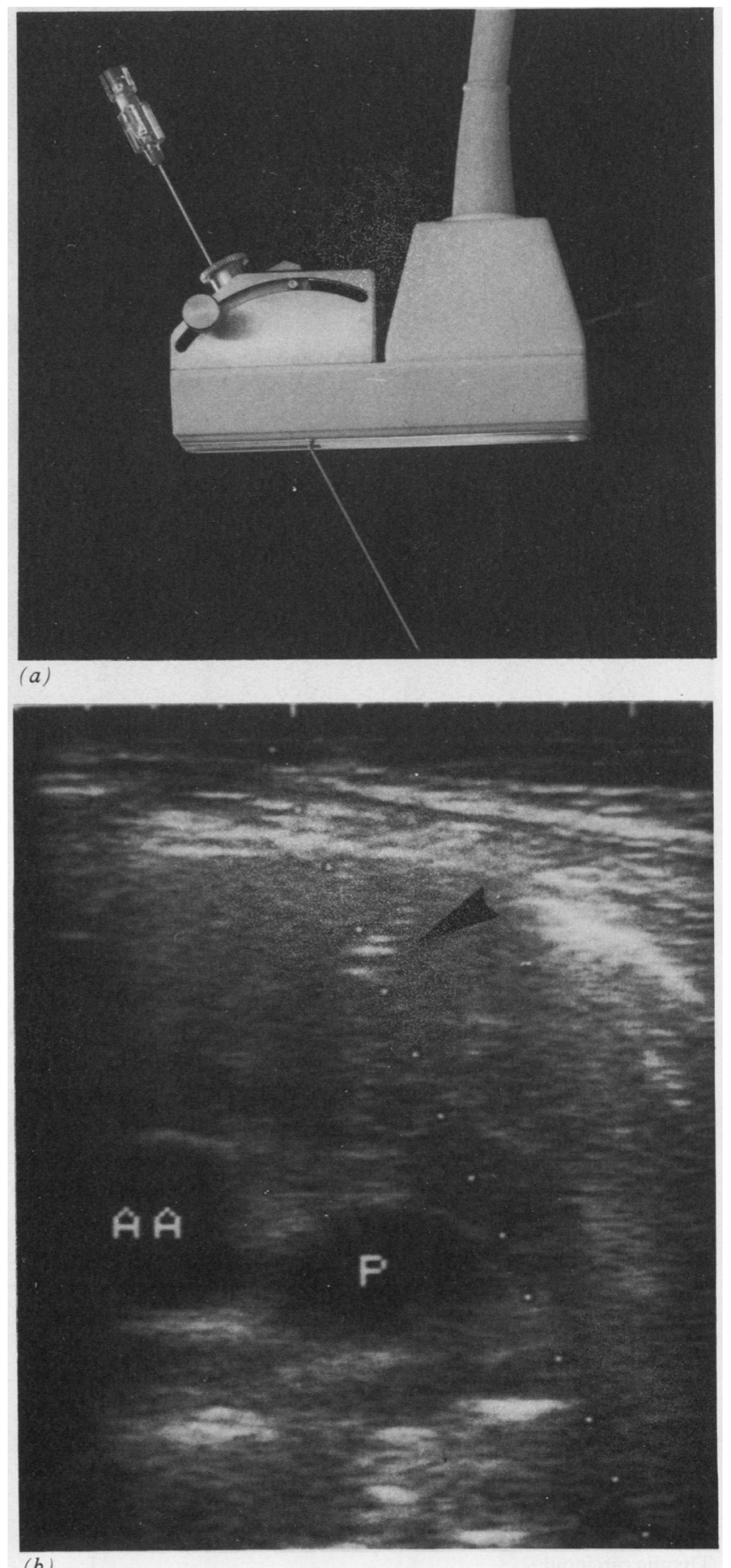

(b)

Figure 1 Technique of sonographically guided biopsy. (a) The biopsy probe equipped with a guide, which can be adjusted to any angle in the range $0-30^{\circ}$. (b) Transverse left parasternal sonogram showing a large tumour anterior to the main pulmonary artery $(P)$ and ascending aorta $(A A)$. To avoid puncture of the internal mammary artery a lateral parasternal approach is selected. By means of an oblique pass (dotted line) the large vessels can be avoided. The tip of the needle is visible as a double reflexion (arrowhead) on the dotted line. Histological examination of the tissue cylinder revealed a Hodgkin's lymphoma of the nodular sclerosing type. 


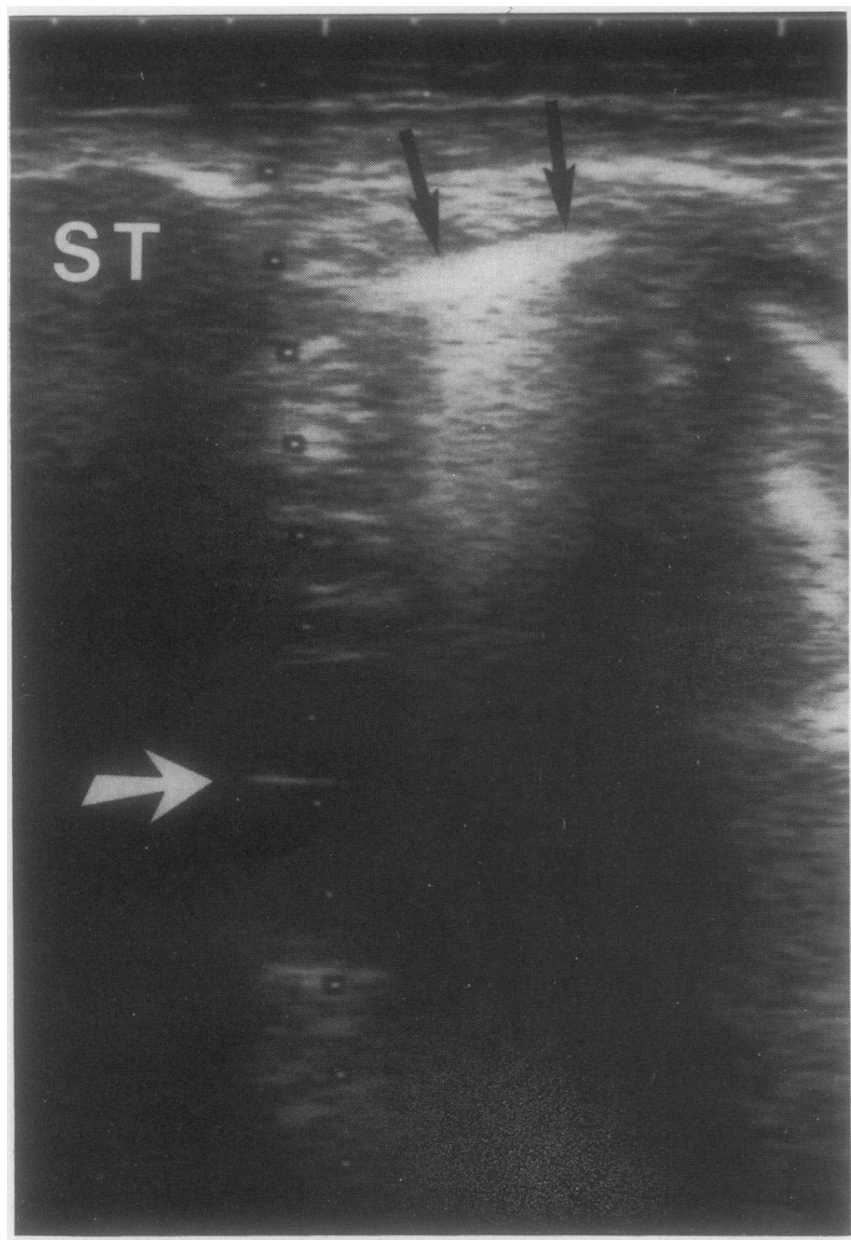

Figure 2 Transverse left parasternal sonogram showing a hypoechoic tumour $(3.5 \mathrm{~cm}$ in diameter) in the anterior mediastinum. To avoid the internal mammary artery an immediate parasternal approach is selected. The tip of the needle can be seen as a hyperechoic reflex (white arrow) within the tumour. Histological examination revealed a

Hodgkin's lymphoma. Black arrows indicate pleura. ST-sternum.

with a 14 gauge cutting biopsy needle (Biopty-cut, Radiplast, Uppsala, Sweden) when tumour size and location permit. As the tip of the Biopty-cut needle is difficult to localise precisely (in millimetres), the large cutting needles should be used only for mediastinal tumours greater than $3.0 \mathrm{~cm}$ in diameter. Biopsies of tumours with a diameter of less than $3 \mathrm{~cm}$ are performed with a 20 gauge or 18 gauge needle (TSK Supra and Surecut, TSK Laboratories,

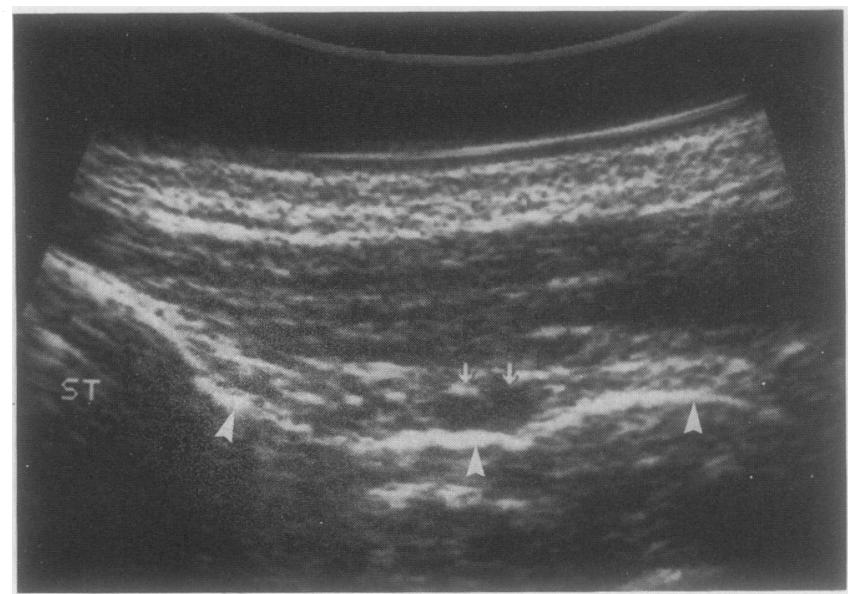

Figure 3 High resolution transverse left parasternal sonogram $(7.5 \mathrm{MHz})$ displaying the exact position of the internal mammary vein and artery (arrows). ST-sternum. Arrowheads indicate pleura.

Tokyo). If mediastinal tumour biopsy is indicated for staging of a malignant tumour of known origin (for example, bronchogenic carcinoma or breast carcinoma), the use of a fine needle ( 20 gauge) is generally sufficient to obtain an adequate diagnosis.

After administration of local cutaneous anaesthesia the needle is inserted through the biopsy sleeve and pushed as far as the tumour under real time control. Rapid repeated insertion and withdrawal of the fine needle and simultaneous aspiration are required to obtain the tissue specimens. Before biopsy with a cutting needle one pass with a fine needle is generally made to assess the consistency and vascularity of the tumour. Further passes with a fine or cutting needle (or both) are done in different parts of the tumour until adequate tissue cylinders are obtained. We generally perform three to five passes even with a large cutting needle, to obtain representative tissue cylinders from different parts of the tumour.

After the biopsy pneumothorax can be excluded initially by sonography. ${ }^{13} \mathrm{We}$ also obtain an expiratory posteroanterior chest radiograph four hours after the biopsy.

RESULTS OF SONOGRAPHICALLY GUIDED BIOPSY

The results of sonographically guided mediastinal tumour biopsies are comparable to those of computed tomography guided biopsies (table). ${ }^{9}$ As the needle can be positioned precisely within anterior and supra-aortic mediastinal lesions under real time control, the results of biopsy depend mainly on the quality of the tissue cylinders and the histological nature of the tumour.

Results of sonographically guided mediastinal tumour biopsy in 24 consecutive patients

\begin{tabular}{|c|c|c|c|c|}
\hline Definitive diagnosis & $\begin{array}{l}\text { No } \\
\text { of } \\
\text { patients }\end{array}$ & $\begin{array}{l}\text { Needle } \\
\text { diameter } \\
(\mathrm{mm})\end{array}$ & $\begin{array}{l}\text { Correct } \\
\text { differentiation } \\
\text { (benign/malignant) }\end{array}$ & $\begin{array}{l}\text { Correct } \\
\text { histological } \\
\text { diagnosis }\end{array}$ \\
\hline \multicolumn{5}{|l|}{ Malignant tumours } \\
\hline Hodgkin's lymphoma & 9 & $\begin{array}{l}2 \cdot 0(n=6) \\
1 \cdot 2(n=2) \\
1 \cdot 0(n=1)\end{array}$ & $\begin{array}{l}6 \\
2 \\
1\end{array}$ & $\begin{array}{l}6 \\
1 \\
1\end{array}$ \\
\hline Non-Hodgkin's lymphoma & 3 & $\begin{array}{l}2 \cdot 0(\mathrm{n}=1) \\
1 \cdot 0(\mathrm{n}=2)\end{array}$ & $\begin{array}{l}1 \\
2\end{array}$ & $\begin{array}{l}1 \\
0\end{array}$ \\
\hline Thymoma & 2 & 1.5 & 1 & 1 \\
\hline Thymic carcinoid & 1 & $2 \cdot 0$ & 1 & 0 \\
\hline \multirow[t]{2}{*}{ Bronchogenic carcinoma } & 2 & $2 \cdot 0(n=1)$ & 1 & 1 \\
\hline & & $1 \cdot 2(n=1)$ & 1 & 1 \\
\hline \multirow[t]{2}{*}{ Breast carcinoma } & 2 & $1 \cdot 2(\mathrm{n}=1)$ & 1 & 1 \\
\hline & & $1 \cdot 0(\mathrm{n}=1)$ & 1 & 1 \\
\hline Adenocarcinoma (uterus) & 1 & $2 \cdot 0$ & 1 & 1 \\
\hline Poorly differentiated small cell epithelial tumour & 1 & $1 \cdot 0$ & 1 & 1 \\
\hline \multicolumn{5}{|l|}{ Benign tumours } \\
\hline Scar tissue after non-Hodgkin's lymphoma & 1 & $1 \cdot 0$ & 1 & - \\
\hline Mediastinal thyroid cyst & 1 & $1 \cdot 0$ & 1 & - \\
\hline Mediastinal haematoma & 1 & $1 \cdot 0$ & 1 & - \\
\hline
\end{tabular}


Percutaneous biopsy is highly accurate in the diagnosis of carcinomas of the mediastinum that have metastasised either from the lung or from extrapulmonary sites. As epithelial metastases are frequently highly cellular, even small tissue specimens are sufficiently representative to obtain an adequate diagnosis.

In general, the results of percutaneous biopsy of mediastinal lymphoma are not as satisfactory as those for carcinoma. In our series the correct histological diagnosis was reached in eight of nine cases of Hodgkin's lymphoma by identification of Reed-Sternberg giant cells in large tissue cores. ${ }^{9}$ In contrast, no definite histological classification was possible in two of three patients with nonHodgkin's lymphoma. This may be related in part to the large amount of reactive inflammatory or fibrotic tissue associated with or surrounding the lymphomatous masses. Pathological differentiation of mediastinal lymphomas and thymomas from a fine needle biopsy specimen and even from histological specimens is difficult. ${ }^{2-4}$ As differentiation between a thymoma, which may require surgery, and systemic lymphatic malignancy is of therapeutic relevance, biopsy needles with a larger diameter (14 gauge) should be used for tumours of adequate size to obtain a large volume of intact tissue. It is important to emphasise that sarcomas and other rare primary mediastinal tumours cannot be diagnosed accurately by percutaneous biopsy even on the basis of large tissue cylinders.

\section{CONCLUSIONS}

Sonographically guided biopsy of mediastinal tumours is a technically simple, rapid and accurate procedure that has all the advantages of spatial orientation offered by computed tomography and, in addition, provides continuous monitoring of the biopsy under real time conditions. Its application is limited, however, by the location of the tumour. In our experience, only tumours of the anterior mediastinum and the supra-aortic region permit safe biopsy with this technique. The main indication for biopsy of an anterior mediastinal lesion is to differentiate between a primary mediastinal tumour that requires surgery and systemic lymphatic malignancy. As histological differentia- tion between lymphomas and thymomas is difficult, cutting biopsy needles of larger diameter should be used initially, when tumour size and location permit. With larger cutting needles the biopsy must be monitored more accurately because the potential risk of vascular trauma increases; real time sonography is ideal for this purpose. In our sample of patients (more than 30 sonographically guided mediastinal biopsies) no complications such as haemorrhage or pneumothorax were encountered despite the increasing use of large cutting biopsy needles.

Institute of Clinical Radiology

KARL WERNECKE

University of Muenster,

Albert-Schweitzer-Str. 33,

D-4400 Münster,

Germany

1 Nordenström B. Paraxiphoid approach to the mediastinum for mediastinography and mediastinal needle biopsy. Invest Radiol 1967;2:141-6.

2 Westcott JL. Percutaneous needle aspiration of hilar and mediastinal masses. Radiology 1981;141:323-9.

3 Thornbury JR, Burke DP, Naylor B. Transthoracic needle aspiration biopsy: accuracy of cytologic typing of malignant neoplasms. AJR 1981;136:719-24.

4 Weisbrod GL, Lyons DJ, Tao LC, Chamberlain DW. Percutaneous fineneedle aspiration biopsy of mediastinal lesions. AJR 1984;143:525-9.

5 Adler OB, Rosenberger A, Peleg $\mathrm{H}$. Fine-needle aspiration biopsy of mediastinal masses. AJR 1983;140:893-6.

6 van Sonnenberg E, Casola G, Ho M, et al. Difficult thoracic lesions: CT guided biopsy experience in 150 cases. Radiology 1988;167:457-61.

7 Wernecke K, Peters PE, Galanski M. Mediastinal tumors: Evaluation with suprasternal sonography. Radiology 1986;159:405-9.

8 Wernecke K, Pötter R, Peters PE, Koch P. Parasternal mediastinal sonography: sensitivity in the detection of anterior mediastinal and subcarinal tumors. $A J R$ 1988;150:1021-6.

9 Wernecke K, Vassollo P, Peters PE, von Bassewitz DB. Mediastinal tumors: biopsy under US guidance. Radiology 1989;172:473-6.

10 Wernecke K, Vassallo P, Pötter R, Lückener HG, Peters PE. Mediastinal tumors: sensitivity of detection with sonography compared with $\mathrm{CT}$ and radiography. Radiology 1990;175:137-43.

11 Glassberg RM, Sussman SK, Glickstein MF. CT anatomy of the internal mammary vessels: importance in planning percutaneous transthoracic procedures. AJR 1990;155:397-400.

12 Scatarige JC, Hamper JM, Sheth S, Allen H. Parasternal sonography of the internal mammary vessels. Technique, normal anatomy and lymphadenopathy. Radiology 1989;172:453-7.

13 Wernecke K, Galanski M, Peters PE, Hansen J. Pneumothorax: evaluation by ultrasound-preliminary results. $J$ Thorac Imag 1987;2:76-8. 